\title{
Difference in Cultural Adjustment of Domestic and International Student Sojourners in Higher Education Institutions
}

\author{
Maliha Nasir ${ }^{*}$ \\ Fazal ur Rahman ${ }^{* *}$
}

\begin{abstract}
In reputed institutions of higher education students come from all over the country for gaining rich experience of learning. Not only Pakistani students from various regions enter in these institutions but also international students get admission in various academic programs. These students encounter various problems related to adjustment in a new environment. Their reaction to these problems and ability to adjust may affect their academic performance. The study mainly aimed at exploring the differences in the ability of domestic sojourners and international students to adjust in a new environment. The sample consisted of 347 students out of which 237 were Pakistani sojourners and 110 were international students. The instrument used for data collection includes Cultural Adjustment Scale which consisted of 22 items. The results revealed that ability to adjust in a new culture positively correlates with academic performance of both local and foreign sojourners. However, the difference between cultural adjustment scores of the two groups was not statistically significant. It is recommended that the institutions should provide sojourner students necessary support so that they would be able successfully complete their academic endeavor.
\end{abstract}

Keywords: Cultural adjustment, international students, domestic sojourners, higher education.

\footnotetext{
*Assistant Professor, Institute of Education, University of Azad Jammu and Kashmir. Email:malihanasir@hotmail.com

***Associate Professor, Early Childhood and Elementary Teacher Education Department, Allama Iqbal Open University, Islamabad
} 


\section{Introduction}

The reputed institutions of higher education in Pakistan cater not only Pakistani students from all over the country but also international students from many other countries. It is a pleasant as well as challenging experience for the students to enter in a culturally and socially different environment for their academic endeavor. They have to face new situations, interact with new people, learn to be independent and adapt to new educational settings. Especially international students have to encounter an environment that may be very different from the one they belong to. In this different environment students have to cope with many problems related to various academic and social matters, e.g. accommodation, food, language, social relations, etc.

Sojourner students bring with them many cultural features that differ from those of the host society. These differences may cause difficulties in communication and dealings with one another. The culture of host society may have such vague features which may be misinterpreted by the sojourners and consequently produce negative feelings in them. How sojourner react to these problems denote their ability of cultural adjustment(Wu, Garza and Guzman 2015).

\section{Literature Review}

In order to develop harmony with the host society, sojourners have to adapt some changes. The process of undergoing these changes refers to as cultural adjustment (Gabel, Dolen and Cerdin, 2005). Cultural adjustment may be defined as a process of accepting and adopting values, beliefs and behaviours of host society in agreement with one' own values (Constantine, Okazaki and Utsey, 2004).

Various studies on adjustment to new culture among international students identified major adjustment problems (e.g. Ruble and Zhang, 2013; Poyrazli and Grahame, 2007; Blake, 2006; Wester, Kuo and Vogel 2006; Mehdizadeh and Scott, 2005; Gong, 2003; Swagler and Ellis, 2003; etc). These problems include adjustment to food, climate, language, etc. which are referred to as general living adjustment. Lee (2014) identified cultural adjustment, language barriers and developing social relationships as three categories of the problems faced by international students.

Other type of problems include familiarizing with educational system and institutional values that is academic adjustment. Sojourners may feel lacking social support of family and friends; and find making 
new friends difficult. These problems are related to sociocultural adjustment.

Khawaja and Dempsey (2008) compared domestic and international students in an Australian university and concluded that both groups differed in their educational expectations and university experience. They also found difference in financial and social support system of both groups. Hechanova-Alampay, Beehr, Christiansen and Van Horn (2002), conducted a longitudinal study on international and domestic sojourners students of an American university. They found that international sojourner students face more difficulty in adjustment than do the domestic sojourners during their initial period in the university.

In a longitudinal study on adjustment of international student, $\mathrm{Wu}$ and Hammond (2011) found that staying in a new country was mostly enjoyable for international university students and they showed satisfactory academic performance. Wu, Garza and Guzman (2015) explored international students' challenges in adjustment to college in America. They found that the international students face transitional difficulties in universities and colleges; however, these challenges motivate them to develop strategies to solve problems.

Mustaffa and Ilias (2013) identified some factors which significantly contribute to cultural adjustment. These factors include level of education, language skills and travel experience. In a study of cultural adjustment experience of Asian students in United States, Constantine, Kindaichi, Okazaki, Gainor and Baden (2005) found both positive and negative emotional responses in the participants. The participants showed excitement about their academic endeavor and personal experiences in the United States. However, they were unhappy for being away from their countries. Alazzai and Chiodo (2006) identified language problems, stress and lack of social support as major problems of international students in making cultural adjustment.

Various studies have provided evidence of the effect of cultural and social adjustment on performance in different fields including education (e.g. Nasir, 2012; Gabel, Dolen and Cerdin, 2005; Chen, Robin and Li, 1997; etc.). Both international and domestic sojourners have to adjust to new environment.

In the light of above discussion this study was conceptualized to examine the difference in the ability of international students and domestic sojourners in Pakistani universities to adjust in a new cultural environment. The study also aimed to find out whether or not cultural adjustment is related to academic achievement of domestic sojourners and international students. The study posits that academic success may 
be affected by cultural adjustment and international students may be more likely to face difficulties in cultural adjustment.

\section{Methodology}

The study is descriptive in nature and survey method was used to collect the data.

\section{Participants}

The participants of the study were randomly selected. The sample consisted of 347 students out of which 237 were Pakistani sojourners and 110 were international students from China, Saudi Arabia, Kenya, Somalia and Turkey. These students were enrolled in the first semester in various study programs of three public universities. The number of male students was 156 and that of female students was 191. The age range of participants was 18 to $32($ Mean=23.67, $\mathrm{SD}=4.09)$.

\section{Instrument}

The instrument used for the study was Cultural Adjustment Scale (CAS) which consisted of 22 items (Nasir, 2012). It has three sub-scales: General Adjustment (GA), Sociocultural Adjustment (SCA) and Work Adjustment (WA). All three sub-scales were correlated with CAS at .01 level revealing the construct validity of CAS. Reliability of the instrument was determined through Cronbach alpha. The value of reliability coefficient for the instrument was .75 showing reasonably high reliability.

\section{Data Analysis}

Statistical software SPSS-17 was used foranalysing the data. Product moment correlation coefficients was calculated for determining the relationship between the variables. The difference in the adjustment ability of international students and domestic sojourners was determined by applying t-test. Regression analysis was performed to determine the extent to which culture adjustment may predict academic achievement of students. 


\section{Results}

The relationship between cultural adjustment and academic achievement was examined by using Pearson Product Moment Coefficient of Correlation. Table 1 shows the coefficients of correlations among the variables for the sample of international students.

The coefficient of correlation $(\mathrm{r}=.29, \mathrm{p}<.01)$ revealed that there was a significant positive correlation between academic achievement and cultural adjustment of international students. The three subscales also had significant positive correlation with academic achievement. General adjustment had correlation coefficient $r=.27$ and Work adjustment had correlation coefficient $\mathrm{r}=.29$ that was significant at $\alpha .01$ level, Sociocultural adjustment also showed significant correlation $(r=.24)$ with academic achievement at $\alpha .05$ level.

Table 1

Coefficients of Correlation of CAS and its 3 Sub-Scales with Academic Achievement of International Students.

\begin{tabular}{lccccc}
\hline & GPA & CAS & GA & SCA & WA \\
\hline GPA & - & & & & \\
CAS & $.29^{* *}$ & - & & & \\
GA & $.27^{* *}$ & $.77^{* *}$ & - & & \\
SCA & $.24^{* *}$ & $.63^{* *}$ & $.35^{* *}$ & - & \\
WA & $.29^{* *}$ & $.84^{* *}$ & $.51^{* *}$ & $.40^{* *}$ & - \\
\hline
\end{tabular}

${ }^{*} \mathrm{P}<.05,{ }^{* *} \mathrm{P}<.01$

Table 2 shows the coefficients of correlations among the variables for the sample of domestic sojourners.The coefficient of correlation revealed no significant correlation of academic achievement with total CAS $(r=.11)$ and its subscale General adjustment $(r=.03)$, $\alpha$ value was higher than .05. The correlation between academic achievement and Work adjustment $(\mathrm{r}=.13)$ was not significant at $\alpha .05$, however, it was only slightly higher than $.05(\mathrm{p}=.057)$, and correlation between academic achievement and Sociocultural adjustment $(\mathrm{r}=.14)$ had $\alpha$ value slightly lower than .05 $(\mathrm{p}=.044)$. 
Table 2

Coefficients of Correlation of CAS and its 3 Sub-Scales with Academic Achievement of Domestic Sojourners.

\begin{tabular}{lccccc}
\hline & GPA & CAS & GA & SCA & WA \\
\hline GPA & - & & & & \\
CAS & $.11^{\mathrm{a}}$ & - & & & \\
GA & $.03^{\mathrm{a}}$ & $.77^{* *}$ & - & & \\
SCA & $.14^{*}$ & $.63^{* *}$ & $.35^{* *}$ & - & \\
WA & $.13^{\mathrm{a}}$ & $.84^{* *}$ & $.51^{* *}$ & $.40^{* *}$ & - \\
\hline
\end{tabular}

${ }^{*} \mathrm{P}<.05,{ }^{\mathrm{a}} \mathrm{P}>.05$

In order to find out the difference in the GPA of domestic sojourners and International students t-test was applied. The mean GPA of domestic sojourner students was 2.87 before getting admission in the university and that of international students was 3.01 (Table 3). The difference in the mean GPA of the two groups $(\mathrm{t}=0.21)$ was not significant at $\alpha .05$ level.

Table 3

Difference in Previous GPA of Domestic Sojourners and International Students.

\begin{tabular}{llllll}
\hline Variable & Students & Mean & SD & SEM & t-values \\
\hline GPA1 & Pakistani & 2.87 & .71 & .049 & $0.21^{\mathrm{a}}$ \\
& International & 3.01 & .51 & .047 &
\end{tabular}

${ }^{\mathrm{a}} \mathrm{P}>.05 \quad(\mathrm{~N}=347$, Pakistani $=237$, International $=110)$

After completing the first semester the domestic sojourners had mean GPA 3.06 and international students had mean GPA 2.75 (Table 4). The result showed that the difference was significant at $\alpha .01$ level $(\mathrm{t}=5.88)$.

Table 4

Difference in the GPA of Domestic Sojourners and International Students after the First Semester.

\begin{tabular}{lllccl}
\hline Variable & Students & Mean & SD & SEM & t-values \\
\hline GPA2 & Pakistani & 3.06 & .81 & .098 & $5.88^{* *}$ \\
& International & 2.75 & .81 & .301 & \\
\hline
\end{tabular}

${ }^{* *} \mathrm{P}<.01 \quad(\mathrm{~N}=347, \quad$ Pakistani $=237$, International= 110 $)$ 
Two groups of domestic students were made on the basis of CAS scores. The students in the high score group had scores on Cultural Adjustment Scale higher than the mean score of the domestic sojourners and the students in the low score group had CAS scores below the mean score. The resultrevealed a significant difference in the mean GPA of the two groups (Table 5). The first group had higher GPA than the second group $(\mathrm{t}=4.057, \mathrm{p}<.01)$.

Table 5

Difference in the Mean GPA of Two Groups of Domestic Sojourners.

\begin{tabular}{llcccc}
\hline Variable & CA Groups & $\begin{array}{c}\text { Mean } \\
\text { GPA }\end{array}$ & SD & SEM & $t$-values \\
\hline GPA2 & High & 3.08 & .654 & .065 & $4.057 * *$ \\
& Low & 2.69 & .736 & .067 & \\
${ }^{* *} \mathrm{P}<.01$ & & $(\mathrm{~N}=237$, & High $=112$, & Low $=125)$
\end{tabular}

Similarly two groups of international students were made. There was a significant difference in the mean GPA the two groups (Table 6).

Table 6

Difference in the Mean GPA of Two Groups of International Students.

\begin{tabular}{llllll}
\hline Variable & CA & Mean & SD & SEM & t-values \\
& Groups & GPA & & & \\
\hline GPA2 & High & 2.95 & .541 & .054 & $4.164^{* *}$ \\
& Low & 2.62 & .631 & .057 & \\
\hline
\end{tabular}

$* * \mathrm{p}<.01(\mathrm{~N}=110, \quad$ High= 62, Low $=48)$

The students in the high score group had higher GPA than the students in the low score group $(t=4.164, \mathrm{p}<.01)$. These results show that difference in cultural adjustment had an effect on academic performance of both domestic sojourners and international students.

Table 7 shows the comparison of the mean CAS scores of domestic sojourners and international students. 
Table 7

Difference in the Mean Scores of Domestic Sojourners and International Students on CAS and Sub-scales.

\begin{tabular}{|c|c|c|c|c|c|}
\hline Variable & Students & Mean & SD & SEM & $t$-values \\
\hline \multirow[t]{2}{*}{ CAS } & Pakistani & 74.74 & 8.94 & .899 & \multirow[t]{2}{*}{$.501^{\mathrm{a}}$} \\
\hline & International & 75.59 & 9.48 & 1.482 & \\
\hline \multirow[t]{2}{*}{ GA } & Pakistani & 27.04 & 3.982 & .401 & \multirow[t]{2}{*}{$.258^{\mathrm{a}}$} \\
\hline & International & 27.24 & 4.826 & .754 & \\
\hline \multirow[t]{2}{*}{ SCA } & Pakistani & 26.17 & 3.639 & .366 & \multirow[t]{2}{*}{$1.419^{\mathrm{a}}$} \\
\hline & International & 27.15 & 3.838 & .599 & \\
\hline \multirow[t]{2}{*}{ WA } & Pakistani & 21.53 & 3.826 & .385 & \multirow[t]{2}{*}{$.472^{\mathrm{a}}$} \\
\hline & International & 21.20 & 3.621 & .565 & \\
\hline
\end{tabular}

There was no significant difference in the two groups on overall cultural adjustment $(\mathrm{t}=.501)$ at $\alpha .05$ level. The scores on three sub scales also showed no significant difference at $\alpha .05$ level: general adjustment $(\mathrm{t}=.258)$, sociocultural adjustment $(\mathrm{t}=$ 1.419) and work adjustment $(\mathrm{t}=.472)$.

Regression analysis revealed thepredictability of cultural adjustment for academic achievement of domestic sojourners and international students. Itrevealed a significant correlation between GPA ofdomestic sojourners and the combined scores onthe subscales of CAS $(\mathrm{R}=$ .201).Cultural adjustment explained $3.8 \%$ variance in the GPA of domestic sojourners $\left(\mathrm{R}^{2}=.038, \mathrm{~F}(3,233)=2.938, \mathrm{p}<.05\right)$.

Standard regression analysis also confirmed that ability of cultural adjustment has significant predictability for academic achievement of international students. There was a significant correlation betweenthe combination of three sub-scales of CAS and the GPA $(\mathrm{R}=.363)$. Cultural adjustment explained $12.9 \%$ variance in GPA of international students $\left(\mathrm{R}^{2}=.129, \mathrm{~F}(3,106)=4.041, \mathrm{p}=.01\right)$.

These results showed that cultural adjustment better predicts academic achievement of International students than that ofdomestic sojourners.

\section{Discussion}

The results of the study implicate that the ability of adjustment may affect academic performance of international students. This result is in agreement with the study of Nasir (2012) who found a significant 
correlation in cultural adjustment and academic achievement of university students; and also corresponds to the findings of Chen, Rubin and $\mathrm{Li}$ (1997) that social adjustment of students significantly correlates with academic achievement.

It is observed in the study that the academic performance of Pakistani sojourners and International students was not significantly different before entering the university (Table 3), however, Pakistani students showed subsequently better results (Table 4). This phenomenon can be explained on the basis of notion that international students face more adjustment problems than do domestic sojourners (Furnham, 2004). The study revealed that students with better adjustment skills in both groups showed better academic performance (Table 5 and 6 ).

The study revealed no significant difference in adjustment abilities of International students and Pakistani sojourners. This finding contradicts with the study of Savicki, Burnette, Heller, Binder, and Suntinger(2004) who concluded that international students have better adjustment abilities than have domestic sojourners.

However, the study revealed that cultural adjustment better predicts academic achievement of International students than that of domestic sojourners. The cultural adjustment of Pakistani students explained only $3.8 \%$ variance in academic achievement $\left(\mathrm{R}^{2}=.038\right)$. However, the cultural adjustment of international students accounted for $12.9 \%$ variance $\left(\mathrm{R}^{2}=.129\right)$ in academic achievement.

The research literature related to adjustment problems provide evidence that international students have to face greater difficulty in adjustment than do domestic sojourners. The initial period of sojourn is more difficult to adjust in which sojourners encounter problems related to physical and emotional wellbeing as well as academic performance. (Hechanova-Alampay, Beehr, Christiansen, and Van Horn, 2002; Furnham, 2004; etc.).

\section{Conclusion and Recommendations}

The study concludes that cultural adjustment may affect academic performance of university students. Though there is no significant difference in adjustment abilities of Pakistani sojourners and International student, the inadequate cultural adjustment may have more negative effect on academic performance of International students than that of Pakistani sojourners.

The institutions of higher education has the responsibility of providing sojourner students, especially international students, necessary support so that they would be able to complete their academic endeavour successfully. The institution may arrange orientation sessions and assign advisors for international students. The interaction with host community may be enhanced through co-curricular activities so that the process of cultural adjustment can be improved. 


\section{References}

Alazzai, K., and Chiodo, J. J.(2006). Uncovering problems and identifying coping strategies of Middle Eastern University students, International Education, 2 (35), 65-105.

Blake A. C. (2006). The experiences and adjustment problems of Africans at a historically black institution, College Student Journal, Retrieved fromhttp://findarticles.com/p/articles/mi_m0FCR/is_4_40/ ai_n27094505

Chen, X., Rubin, K. H. and Li, D.(1997) Relation between academic achievement and social adjustment: Evidence from Chinese children, DevelopmentalPsychology, 3 (33), 518-525.

Constantine, G. M., Kindaichi, M., Okazaki, S., Gainor, K. A. and Baden, A. L. (2005) A qualitative investigation of the cultural adjustment experience of Asian International College Women, Cultural Diversity and Ethnic Minority Psychology, 2 (11), 162- 175

Constantine, M. G., Okazaki, K. and Utsey, S. O. (2004). Selfconcealment, Social Efficacy, Acculturative Stress and Depression in African, Asian and Latin America International College Students, American Journal of Orthopsychiatry, 3 (74), . 230-241.

Furnham, A. (2004). Foreign Students: Education and Culture Shock, The Psychologist, 1 (17), 16-19.

Gabel, R. S., Dolan, S. L. and Cerdin, J. L. (2005). Emotional Intelligence as Predictor of Cultural Adjustments for Success in Global Assignments, Career Development International, 5 (10), 375-395.

Gong, Y. (2003). Goal orientations and cross-cultural adjustment: an exploratory study, International Journal of Intercultural Relations, 3 (27), . 297-305

Hechanova-Alampay, R., Beehr, T. A., Christiansen, N. D. and Van Horn R. K. (2002). Adjustment and Strain among Domestic and International Student Sojourners, School Psychology International, 23 (4), 458-474. 
Khawaja, N. G. and Dempsey, J. (2008). A comparison of International and Domestic Tertiary Students in Australia. Australian Journal of Guidance \& Counselling, 18 (1), 30-46.

Lee, K. C. (2014) Tips for International Students' Success and Adjustment, International Student Experience Journal, 2 (1), Retrieved from www.uwest.edu\%2Fsite $\% 2$ Ffile $\% 2$ Fdocs $\% 2$ Fpubs $\% 2$ Ffaculty\%2FDr_George_Lee_Tips\%2520for\%2520International $\% 2520$ Students $\% 25 \mathrm{E} 2 \% 2580 \% 2599 \% 2520$ Success $\% 2520$ and $\% 252$ 0Adjustment.pdf

Mehdizadeh, N. and Scott, G. (2005) Adjustment problems of Iranian international students in Scotland, International Education Journal, 6 (4). 484-493.

Mustaffa, C. and Ilias, M. (2013). Relationship between Students Adjustment Factors and Cross Cultural Adjustment: A Survey at the Northern University of Malaysia, Intercultural Communication Studies 1 (22), 279-300.

Nasir, M. (2012). Effects of Cultural Adjustment on Academic Achievement of International Students. Journal of Elementary Education 2 (22), 95-103.

Poyrazli, S. and Grahame, K. M. (2007). Barriers to Adjustment: Needs of International Students within a Semi-Urban Campus Community, Retrieved from http://www.redorbit.com/news/education/907480/barriers_to_adjustmen t_needs_of_international_students_within_a_semiurban/index.html

Ruble, R. A. and Zhang, Y. (2013). Stereotypes of Chinese IS held by Americans. International Journal of Intercultural Relations, 37 (2), 202-211.

Savicki, V., Burnette, R., Heller, L., Binder, F. and Suntinger W. (2004) Contrasts, Changes and Correlates in Actual and Potential Intercultural Adjustment, International Journal of Intercultural Relations, 28 (2004), . 311-329 
Swagler, M. A. and Ellis M. V.(2003). Crossing the Distance: Adjustment of Taiwanese Graduate Students in the United States, Journal of Counseling Psychology, 52 (4), 527-536.

Wester, S.R., Kuo, B. C. H. and Vogel, D. L. (2006). Multicultural Coping: Chinese Canadian Adolescents, Male gender role conflict and psychological distress, Psychology of Men and Masculinity, 7, 2, $83-100$.

Wu, W. and Hammond, M. (2011). Challenges of university adjustment in the UK : a study of East Asian Master's degree students. Journal of Further and Higher Education, 35 (3). 423-438.

Wu, H., Garza, E. and Guzman, N. (2015). International Student's Challenge and Adjustment to College, Education Research International, Retrieved from http://www.hindawi.com/journals/edri/ 2015/202753/

\section{Citation of this Article:}

Nasir, M. (2017). Difference in cultural adjustment of domestic and international student sojourners in higher education institutions. Pakistan Journal of Education, 34 (1), 55-66.

Received on: 11 Nov 2016

Revised on: 20 April, 2017

Accepted on: 10 June, 2017 